Revista do Departamento de Geografia
Universidade de São Paulo
www.revistas.usp.br/rdg

\title{
Feiras e Mercados Municipais em Bocaiúva (MG) e Montes Claros (MG): O Empoderamento das Mulheres Agricultoras
}

\author{
Fairs and Municipal markets of Bocaiúva (MG) and Montes Claros (MG): \\ Empowering Women in Agriculture
}

\author{
Ana Ivania Alves Fonseca \\ Universidade Estadual de Montes Claros \\ anaivania@gmail.com \\ Silviane Gasparino Costa \\ Universidade Estadual de Montes Claros \\ silviane-gaspar@hotmail.com \\ Genilda do Rosário Alves Lima Vieira \\ Universidade Estadual de Montes Claros \\ genildaalves.lima@yahoo.com.br \\ Sanndy Maria Gonçalves Galdino \\ Universidade Estadual de Montes Claros \\ sanndygoncalves@yahoo.com.br
}

Resumo: As feiras e os mercados municipais no Norte de Minas são locais onde são manifestas relações culturais. Há o entrelaçamento entre o urbano e o rural por meio dos produtos comercializados e do contato entre os agricultores familiares e a população urbana. Para as agricultoras familiares dos municípios de Montes Claros (MG) e Bocaiúva (MG), a feira, nesses mercados, não só possibilita o ganho financeiro, mas também são locais de socialização de seus saberes e de qualidade de vida. A maioria das mulheres agricultoras que participa das feiras relata estar satisfeita com a comercialização de seus produtos nesses espaços e que não troca essa atividade por um trabalho na cidade com carteira assinada. Assim, este trabalho objetiva verificar o acesso das mulheres rurais aos mercados e feiras como forma de construção de sua identidade social.

Palavras-chave: Feiras, Mercados Municipais, Trabalho, Mulheres Agricultoras, Crédito rural.

\begin{abstract}
Municipal fairs and markets in The North of Minas Gerais State are places where cultural relations are manifested. There is an intermingle between urban and rural through marketed products and the contact between farmers and urban population. For women of family farming from the municipalities of Montes Claros(MG) and Bocaiuva (MG), the trade in these markets not only allows financial gain, but it also promotes socialization of their knowledge and life quality. Most women farmers participating in the fair reported being satisfied with the marketing of their products in these areas and that they do not change this activity for a job with a formal contract in the city. Thus, this study aims to investigate the access of rural women to markets and fairs as a way of building their social identity.
\end{abstract}

Keywords: Trade, Municipal Markets, Job, Women Farmers, Rural Credit. 


\section{INTRODUÇÃO}

Entender a inserção da mulher no mercado de trabalho é algo que certamente demanda uma análise muito próxima do seu cotidiano. Em qualquer atividade de trabalho, seja ela econômica ou não desenvolvida pela mulher semelhante à desenvolvida pelo homem, o reconhecimento, na maioria das vezes, não é o mesmo. Quando essa análise perpassa pela mulher rural, o seu trabalho se torna ainda mais sem visibilidade.

A partir do momento em que a mulher desafia as relações familiares patriarcais, criando espaço para novas abordagens e perspectivas por meio do empoderamento, está implicando mudanças não só em suas próprias experiências, mas também nas de seus companheiros e de sua família, além de ocorrer a construção de uma nova identidade (VIEIRA et al., 2013).

Nesse sentido, a inserção e manutenção das mulheres nas feiras têm concedido a elas diversas possibilidades de ganhos, principalmente o financeiro, e, cada vez mais, a mulher vem-se mantendo e criando uma rede de sociabilidade para além do núcleo familiar.

Assim, este trabalho teve como objetivos analisar o empoderamento da mulher por meio do seu trabalho e da participação nas feiras e mercados das cidades de Bocaiúva (MG) e Montes Claros (MG); descrever a importância das feiras como lugar de convívio e troca de informações sociais; e a relevância do crédito rural como subsídio à produção de suas mercadorias.

\section{MATERIAIS E MÉTODOS}

A metodologia utilizada foi construída em três etapas. Primeiramente foi feita pesquisa bibliográfica em livros, periódicos, teses e nas linhas de crédito do Programa Nacional de Fortalecimento da Agricultura Familiar - PRONAF no site do Ministério do Desenvolvimento Agrário - MDA (2015).

A segunda etapa baseou-se no trabalho de campo nos mercados de Bocaiúva (MG) e Montes Claros (MG) com o objetivo de realizar entrevistas semiestruturadas e diálogos com as mulheres que participam das feiras nesses mercados. As entrevistas foram gravadas para posterior transcrição, o que garantiu a fidelidade do que foi dito pelas agricultoras entrevistadas.

Nas visitas in loco foram coletados material iconográfico, visto que a utilização de fotos e de mosaicos no trabalho facilita a interação e visualização pelo leitor da realidade estudada pelos pesquisadores.

Para localização das áreas estudadas elaborou-se um mapa localizando os mercados municipais dentro da área dos municípios estudados. A área dos mercados foi vetorizada utilizando-se imagem extraída do Google Earth. O georreferenciamento da imagem e montagem do mapa foram feitos por meio do programa ArcGis 10.2.1 (ESRI, 2013). Também, utilizou-se de dados do IBGE (2010). Os principais povoados e a rodovia que interliga os municípios foram identificados no mapa. A última etapa do trabalho foi a redação do texto com a junção dos dados coletados e sistematizados.

\section{RESULTADOS E DISCUSSÃO}

\subsection{Participação da Mulher nas Feiras e Mercados}

A feira e o mercado são pontos de exposição de mercadorias em que vendedores e compradores se reúnem em dias e locais pré-determinados para exposição, apreciação e compra de mercadorias. Segundo Barbosa (2003, p.62), "[...] a diferença entre o mercado e a feira está no tempo que decorre a realização de cada um". No mercado realizam-se encontros que se repetem a curtos intervalos, geralmente diários, fazendo parte de curtos ciclos de troca. Já as feiras precisam de um espaço de tempo maior para sua realização, comumente ocorrem nas sextas-feiras, sábados e domingos.

As feiras nos mercados municipais constituem local em que vão sendo escritas as várias histórias, tanto das agricultoras e agricultores familiares que os utilizam, quanto da sociedade que mantém, nesses locais, relações comerciais, laços de sociabilidade e convivência (FONSECA et al., 2009). As feiras possibilitam o acesso das agricultoras ao mercado, tido como um dos mais importantes pontos de comercialização dos seus produtos. A estrutura dos mercados municipais possibilita às mesmas a ativação de sua força de trabalho. Os mercados são instituições presentes, principalmente, nas cidades do interior de Minas Gerais (Figura 1), apresentam-se de formas diferentes, estando em conformidade com o ambiente em que são estabelecidas as relações culturais do lugar. 
Em entrevistas feitas nos dois mercados em estudo, as agricultoras estabeleceram os seguintes relatos sobre a importância da feira em suas vidas:

Agricultora 1- [...] "é bom porque a gente conhece novas pessoas. Você atende um freguês e tem amizade com aquele freguês".

Agricultora 2 - "é muito importante porque ajuda na renda da minha família".

Agricultora 3 - [...] "aqui eu vendo as coisas que tenho em casa e troco pelo que preciso".

Agricultora 4 - "Dependo dela pro sustento".

(ENTREVISTAS REALIZADAS NOS MERCADOS CENTRAIS DE BOCAIÚVA(MG) E MONTES CLAROS(MG), 2015 e 2016).

As feiras, conforme relatos possuem grande valor financeiro para essas produtoras rurais, já que para algumas é a principal forma de sustento de seu núcleo familiar. No entanto, esses ambientes vão além do comércio, tornando-se pontos de socialização, troca de informações e conhecimentos. Além disso, a feira nos mercados municipais permite que as produtoras façam trocas de produtos entre si, contribuindo, dessa forma, com a reposição dos objetos que precisam em casa.
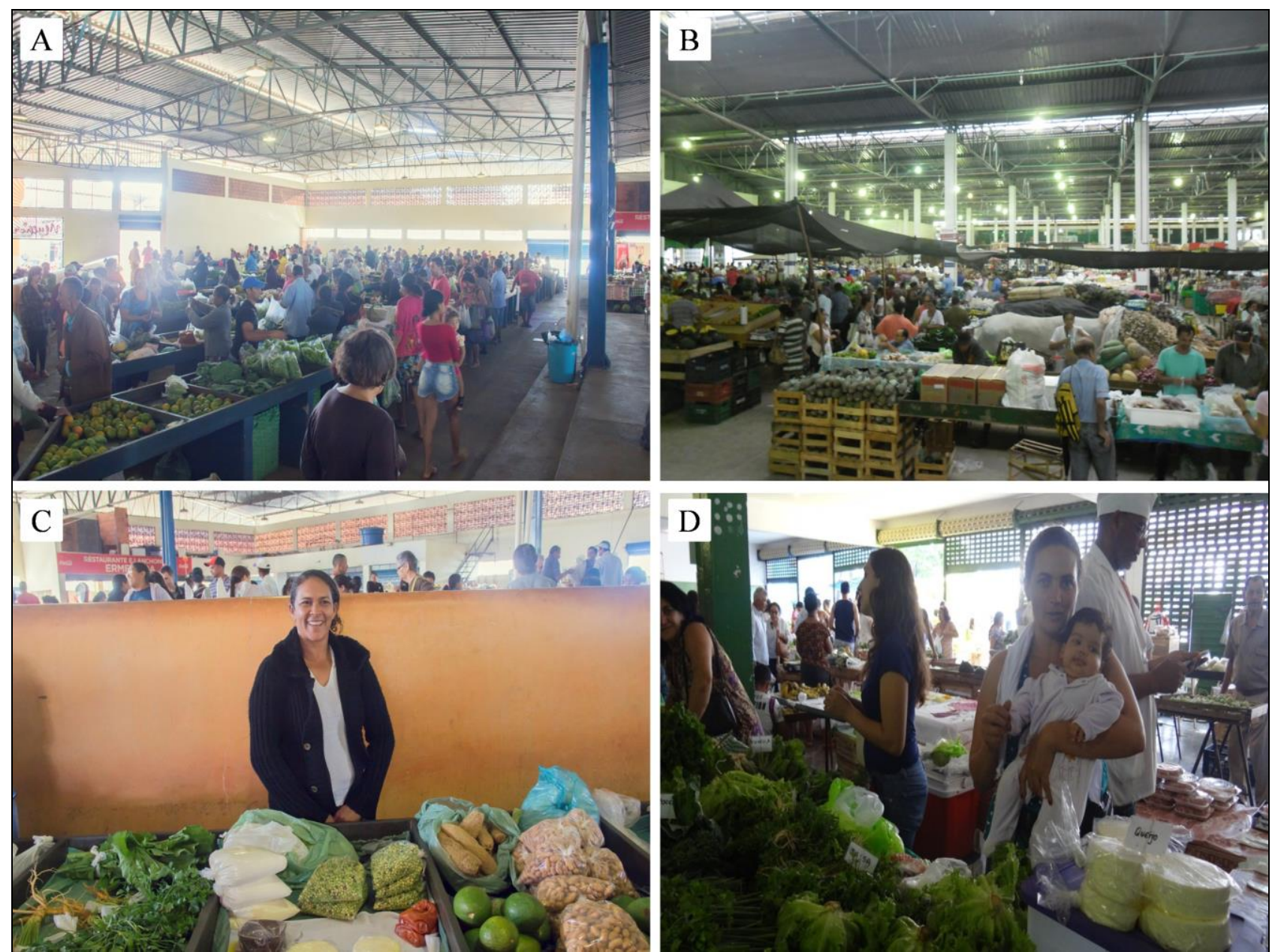

Figura 1: Visualização dos mercados rurais e feiras agrícolas dos municípios em estudo: [A] mercado rural de Bocaiúva (MG); [B] mercado rural de Montes Claros (MG); [C] feirante do mercado de Bocaiúva (MG) e; [D] feirante do mercado de Montes Claros(MG).

Na Figura 1 pode-se visualizar as atividades comerciais dos mercados municipais e as feiras acontecendo no mesmo espaço. Feirantes no geral, agricultores e agricultoras familiares de várias comunidades de Montes Claros (MG) e Bocaiúva (MG), utilizam a estrutura física de seus mercados para vender seus diferentes produtos da feira. Dessa maneira, os espaços das feiras e mercados são lugares de identidades e tradições de determinados grupos sociais, em que esses acabam, na realidade, misturando-se entre trabalho e 
entretenimento, mas, sobretudo, são lugares propícios aos encontros e convivência entre as pessoas que deles participam (FONSECA et al., 2009). Para Carneiro (2008, p.259),

[...] diferentemente do trabalhador assalariado, a unidade familiar de produção, por ser sustentada pela íntima relação entre trabalho e parentesco, apresenta maior margem de negociação interna na elaboração de caminhos alternativos de reprodução social.

O trabalho feito em uma unidade de produção familiar acarreta em uma maior autonomia de seus membros, o que traz uma "[...] noção de liberdade associada ao trabalho por conta própria" (CARNEIRO, 2008, p.260).

Destarte, em determinada fase das entrevistas com as agricultoras dos mercados, foi feito o seguinte questionamento: Trocaria as atividades da feira por emprego formalizado (com carteira assinada)? Aquelas fizeram os seguintes relatos:

[...] "Não. Porque consigo conciliar o trabalho aqui e trabalhar na minha casa na roça" (AGRICULTORA DE BOCAIÚVA, JANEIRO DE 2016).

[...]. "às vezes o emprego de carteira assinada pode até dar mais, mas eu olho pelo lado pessoal, porque se eu não quiser trabalhar hoje, eu não trabalho e, empregada, eu sou obrigada a trabalhar oito horas por dia. Na feira, se eu não quiser vir eu não venho. Então, eu faço a minha mercadoria, tem dias na semana que eu estou mais tranquila que eu faço outras atividades, como o artesanato e trago para vender, então é um complementando o outro. E eu empregada eu não teria este complemento e só teria um dia de folga para fazer as minhas atividades de casa. E assim, consigo conciliar as minhas atividades de casa e fazer os meus produtos que eu trago para cá para vender (faço os dois juntos). Eu prefiro assim. Eu já até tive uma proposta de emprego, só que eu falei, assim, não, pode passar para outra pessoa. Enquanto eu puder trabalhar assim, eu prefiro assim, do que trabalhar fichado" (AGRICULTORA DE MONTES CLAROS(MG), MARÇO DE 2015).

Desse modo, pode-se perceber que, para essas mulheres, trabalhar nas feiras dos mercados é desenvolver uma atividade, que, além de oferecer benefícios financeiros, possibilita-lhes manterem-se presentes em seus lares para o seguimento de suas atividades domésticas e com presença ativa na criação de seus filhos. Carneiro (2008, p.261) salienta que,

Se levarmos em conta, por exemplo, que, além dos bens materiais, outros tipos de bens, simbólicos, são transmitidos de uma geração a outra, iremos observar o papel-chave desempenhado pela mulher na dinâmica dessas famílias, não apenas como elemento da produção, do trabalho, mas como elemento da reprodução: como guardiãs e transmissoras privilegiadas de valores.

A feira nos mercados para essas pequenas produtoras rurais se constitui em lugar de oportunidades e ganhos, sendo esses o financeiro, o social, o familiar e o da liberdade. Sobre a feira, Barbosa (2003, p.8) analisa:

[...] neste espaço há, sobretudo democracia, pois se entrelaçam urbano e rural, onde as pessoas oriundas desses dois universos, de diferentes classes sociais, entrecruzam-se no ambiente da feira e tecem relações de amizade.

É nesse espaço que a mulher trabalhadora se coloca como autora da sua vida social, pois a ela cabe a produção e a comercialização, negociando e comprando. Ao mesmo tempo em que elas vendem os seus produtos, criando uma relação com o espaço, também se veem como produtoras desse e como um elemento forte dentro dessa construção. $\mathrm{O}$ fato de muitas delas saírem de suas propriedades, dirigindo o seu carro ou de outra forma, mas que não seja diretamente dependendo do marido, fazem-nas mais fortes e isso tem se tornado cada vez mais comum nas feiras das cidades de Montes Claros (MG) e Bocaiúva (MG). E essas ações, de certa forma, constituem o empoderamento de tais mulheres. 
A noção de empoderamento (empowerment) tem suas raízes nas lutas pelos direitos civis no movimento feminista e na ideologia da "ação social", presentes nas sociedades dos países desenvolvidos na segunda metade do século XX (HERNÁNDEZ, 2009, p.64).

O empoderamento é uma maneira de mudar, centralizando-se no poder, definindo padrões nas relações sociais, econômicas e culturais. Assim, Hernández (2009, p.65-66), apud Stromquist (1997), contextualiza o empoderamento econômico individual como "[...] melhoria da qualidade de vida" das mulheres e de suas famílias.

Entretanto, não se pode falar de feira/mercados municipais sem estabelecer os vínculos e as relações sociais e culturais existentes no interior desses espaços; assim, enquanto as cidades vão crescendo e oferecendo às pessoas cada vez mais modernidade, as feiras/mercados vão permanecendo ali no mesmo local, sem sofrer muitas alterações e mantendo em seu interior os mesmos fluxos de amizade e relações que estão entrelaçadas no cotidiano das pessoas que participam. Para Ribeiro et all. (2007, p.83 e 85):

A feira livre é uma das instituições mais sólidas de Minas Gerais, principalmente no norte, nordeste e noroeste do Estado. Ela faz parte da economia e da cultura dessas regiões. [...] criam e colocam em circulação recursos que alimentam a população urbana e contribuem para a soberania alimentar. As feiras livres beneficiam os agricultores, o comércio urbano e os consumidores.

$\mathrm{O}$ termo feira remete a uma soma de coisas peculiares, que se misturam em cores, sabores, cheiros e que, durante séculos, vem-se repetindo e se aperfeiçoando como um ritual quase que sagrado feito pelo homem. É nesse espaço que as trabalhadoras rurais têm-se situado e colocado os seus produtos. A diversidade e sutileza desses produtos vêm fortalecendo cada vez mais as feiras e mercados que no município de Montes Claros (MG) acontecem nas sextas-feiras, sábados e, aos domingos, em locais e bairros diferentes. Em Bocaiúva (MG), as feiras ocorrem nos mercados às sextas-feiras e aos sábados.

Percebemos, desde a produção de flores, produtos do artesanato, passando por hortifrutigranjeiros até os pré-fabricados por elas como o beiju - feito da fécula da mandioca; ou a rapadura - retirada da cana-deaçúcar.

Os mercados municipais em estudo são subdivididos em bancas de feirantes da agricultura familiar e de comerciantes no geral (Figura 2). Os agricultores e agricultoras vendem produtos não processados como as hortaliças, frutas, verduras e legumes; e produtos processados, como beiju, rapadura, doces, temperos diversos, queijos, requeijões, entre outros. Os mercados possuem, também, boxes de lojas de roupas e calçados, restaurantes de comidas típicas, peixarias, mercearias, bares e açougues.

Os mercados municipais representam para as populações locais e regionais um elo entre o rural e o urbano. A cultura regional se manifesta nesses espaços por meio das danças regionais, das comidas típicas, apresentações de grupos folclóricos, além da comercialização de produtos cultivados nesses municípios e na mesorregião norte-mineira (BARBOSA, 2012). Esses ambientes possibilitam o entretenimento e o encontro das diferenças em um único lugar.

Nesse sentido, os espaços ocupados pelas feiras e mercados abarcam vários tipos de mercadorias; pessoas que vendem e compram essas mercadorias; causos contados e recontados pelos seus visitantes; "é uma pechincha aqui, outra pechincha ali"; fregueses amigos dos vendedores, ou seja, uma afetividade pelo lugar. Assim, Boechat e Santos (2009, p. 6-7) descrevem:

As feiras livres têm esse caráter diversificado, onde circulam por elas vendedores, compradores, transeuntes, personagens e outros participantes variados. Essas pessoas circulam muito, examinam, pechincham, ou simplesmente estão à procura do que desejam, sendo que outras já têm seus feirantes preferidos, conhecem estes de longas datas, e às vezes criam laços de afetividades mais profundos, tornando mais amigos do que fregueses, no meio desta distribuição, surgem os ambulantes, transportadores, os contadores de histórias, gerando assim um verdadeiro "tumulto" perfeitamente arranjado onde acaba funcionando de maneira certa e atendendo a todos em seus anseios. 


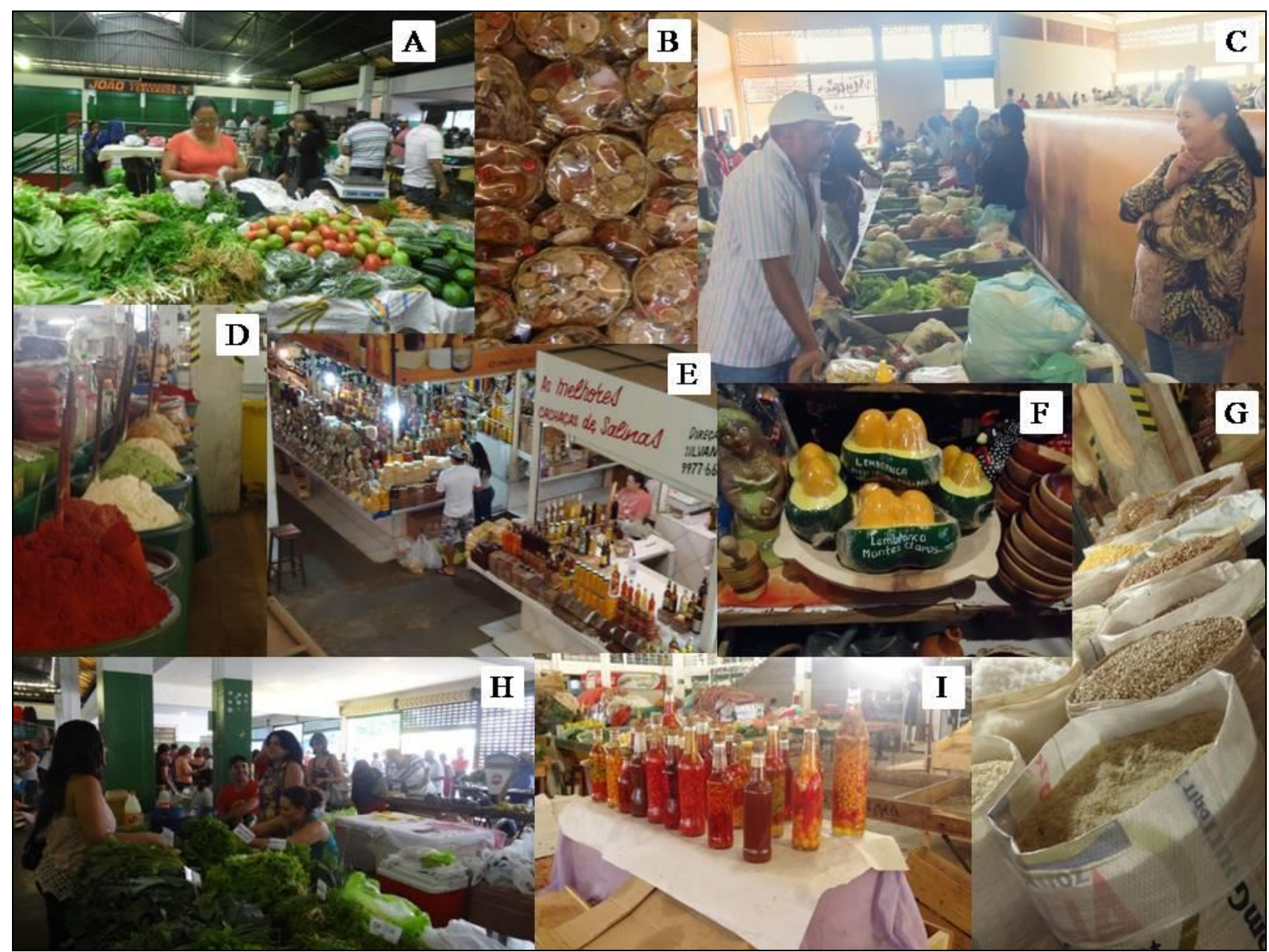

Figura 2: Produtos vendidos nos Mercados Municipais de Bocaiúva (MG) e Montes Claros(MG): [A] feira de hortaliças e verduras no mercado de Montes Claros(MG); [B] doces; [C] feira de verduras e legumes no mercado de Bocaiúva(MG); [D] temperos diversos; [E] estande de produtos no mercado de Montes Claros(MG); $[\mathrm{F}]$ artesanato; $[\mathrm{G}]$ sacas de grãos e farinhas; $[\mathrm{H}]$ feira de hortaliças e; [I] pimentas em conserva.

Portanto, a feira é um espaço de socialização de saberes, lazeres, compra e venda; é decisivamente uma forma de identidade cultural e comercial que beneficia todos os atores envolvidos no seu processo de formação e organização. Na Figura 3, podem-se visualizar os municípios de Montes Claros (MG) e Bocaiúva (MG) e a localização de seus mercados municipais.

A Figura 3 foi organizada a partir dos shapes dos municípios de Bocaiúva (MG) e Montes Claros (MG) e da localização dos povoados presentes em cada município (IBGE, 2010). Foi feita a localização dos mercados e a vetorização das áreas a partir de imagens do software livre Google Earth, 2013. Depois de realizada a vetorização das imagens, essas foram extraídas para visualização na Figura 3. A BR 135 foi localizada porque faz a ligação entre as duas municipalidades. Todos os processos feitos nessa figura foram executados por meio do programa ArcGis 10.2.1.

As agricultoras familiares que participam da feira, nos mercados municipais de Bocaiúva (MG) e Montes Claros (MG), têm suas propriedades localizadas nas proximidades da sede dos municípios. Segundo os dados coletados por meio da aplicação das entrevistas nas feiras municipais, destaca-se a participação de várias agricultoras de outros municípios, mas, é nos limites entre o município de Montes Claros (MG) e Bocaiúva (MG) que há maior participação, com agricultoras vindas de várias comunidades rurais. Destaque especial é dado à comunidade do Planalto Rural, localizada no município de Montes Claros(MG), às margens da BR 135, que disponibiliza agricultores e agricultoras feirantes para os mercados das duas cidades em estudo. Nessa comunidade, as mulheres têm uma organicidade que as leva a acessar de forma constante as linhas de crédito do PRONAF. Foi a partir dessa organização, tanto da produção quanto no acesso aos financiamentos, que as mulheres tiveram um maior ingresso nas feiras desses municípios. 


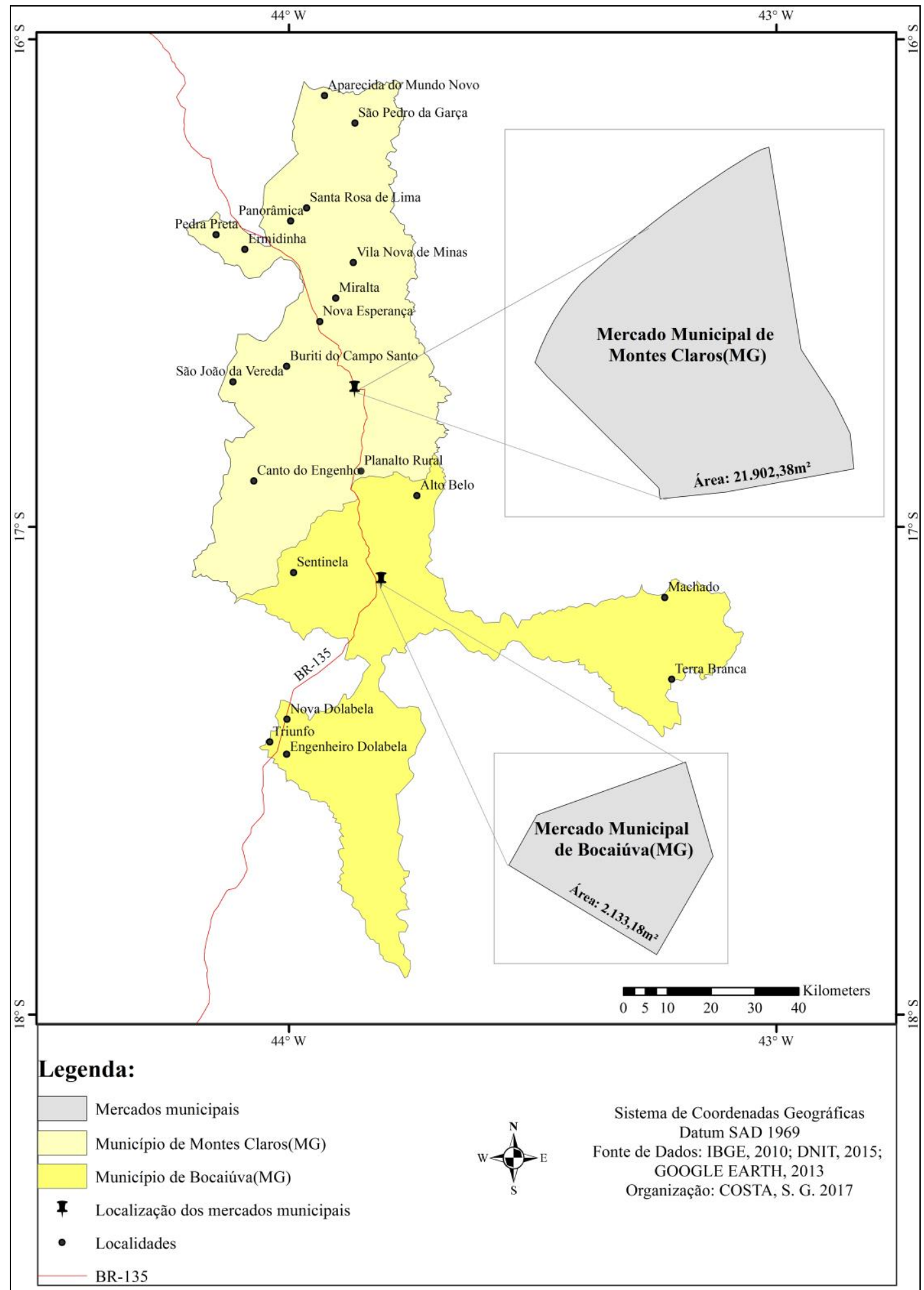

Figura 3: Localização dos mercados municipais de Montes Claros (MG) e Bocaiúva (MG).

\subsection{O Acesso da Mulher ao PRONAF}

A feira é abastecida pela agricultura familiar e essa precisa de apoio governamental para preparação dos solos, compra de sementes, maquinários e utensílios agrícolas. Na atualidade, a agricultura familiar vem recebendo fomento econômico para sua produção e reprodução por meio de programas do governo, como o Programa Nacional de Fortalecimento da Agricultura Familiar - PRONAF e o Programa de Aquisição de Alimentos - PAA que vêm contribuindo de forma significativa para a melhoria de vida, tanto social quanto econômica dos agricultores, levando a uma maior produção e, consequentemente, refletindo em produtos de melhor qualidade nas feiras (FONSECA, 2014). 
O PRONAF é um programa destinado ao apoio financeiro das atividades Agropecuárias. Antes proposto apenas aos homens e, a partir do Plano Safra (2003-2004), reconhece o trabalho da mulher produtora rural por meio do PRONAF-Mulher, tendo como finalidade o atendimento de propostas de crédito da mulher agricultora.

O PRONAF-Mulher ainda é pouco acessado pelas mulheres rurais dos municípios do Norte de Minas, incluindo Montes Claros (MG) e Bocaiúva (MG). Trata-se de uma linha especial que teve seu acesso facilitado mediante garantia de uma operação a mais por família, independentemente do crédito que tenha sido contratado pelo grupo familiar. O pouco acesso acontece, principalmente, pelo fato de haver certa dependência da mulher em relação à situação do marido (inadimplência em relação a outras linhas de crédito) para poder acessar os recursos e dos técnicos das instituições de acesso ao crédito para elaboração do projeto, que nem sempre sai de acordo com os interesses das mulheres.

Nos municípios pesquisados, as mulheres têm trabalhado com o PRONAF - B e com o PRONAFINHO. Essa última linha foi instituída pela resolução $n^{\circ} 2.436$ de 21 de outubro de 1997. É uma linha especial de crédito, de acesso mais fácil e rápido para pequenos agricultores familiares com renda abaixo da média. De fato, percebe-se que, a partir do financiamento com juros mais baixos, a mulher tem-se lançado cada vez mais em melhorar sua produtividade e sua renda. Usando o financiamento para diversas finalidades, desde o cercamento das hortas à melhoria no plantio, com a compra de sementes de melhor qualidade, e no escoamento das mercadorias. Isso reflete diretamente no cotidiano das mulheres, pois visivelmente a mulher trabalhadora rural tem deixado de lado certo ar de mulher sofrida e adquirido um aspecto de mulheres que se inserem, de fato, no cotidiano da vida, adquirindo autonomia e maior independência, transformando-se em um ser ativo nas decisões acerca dos processos produtivos; abandona, então, o papel de "coadjuvante" e assume o protagonismo agrícola, de fato.

Nos dias de feira, o local e seu entorno ficam movimentados; às sextas e aos sábados elas chegam cedo, vêm de diferentes comunidades rurais. As maneiras de chegar até as feiras são variadas, algumas vêm de ônibus fretado, outras de carros próprios, outras dividindo caronas entre elas ou com seus cônjuges. As bancas já são pré-definas, tanto nas feiras dos mercados centrais, quanto nas feiras dos bairros que, normalmente, acontecem aos domingos pela manhã. Sobre isso, Ribeiro et al. (2007, p.87) expõe:

[...] Os feirantes ocupam espaços bastante reservados para suas trocas periódicas, que não são regulados somente pelas normas que vigoram nos grandes mercados, mas pautados pela particularidade, pela solidariedade, pela complementaridade, pela informalidade que resultam da sedimentação histórica dessas relações locais.

As mulheres feirantes chegam muito cedo a fim de arrumar os seus produtos da melhor maneira possível para apreciação dos fregueses que, como de costume, chegam também muito cedo. A partir das 6 horas da manhã, já se observam pessoas em busca dos melhores produtos (os mais fresquinhos) que vão desde a farinha de mandioca, requeijões de forma ou de prato, farinha de milho, beijus, queijos, biscoitos caseiros e várias opções de hortifrutigranjeiros, tudo produzido nas chamadas indústrias rurais.

Mas a feira para as mulheres não é apenas um lugar específico para comercialização dos seus produtos, é, acima disso, um lugar de sociabilidade e de manutenção da cultura, de trocas de receitas e indicação de cursos que vão acontecer na comunidade, de compra de roupas e calçados ao convite para as festas e almoços nas comunidades. 


\section{CONSIDERAÇÕES}

Considera-se que por meio do trabalho nas feiras e mercados dos municípios de Bocaiúva (MG) e Montes Claros (MG) a mulher agricultora se impõe como autora de sua vida social. Nesses locais se torna possível a comercialização dos produtos da agricultura cultivados por elas. Também, potencializam os seus rendimentos, produzindo o artesanato e produtos processados com as matérias-primas advindas de suas propriedades rurais.

O acesso às linhas de crédito do PRONAF, especialmente do PRONAF-B, possibilita o investimento na infraestrutura de suas propriedades, na aquisição de equipamentos para o plantio, colheita e processamento da produção. A logística de transporte também é possibilitada por meio do financiamento do PRONAF.

Assim, as feiras nos mercados são apresentadas pelas agricultoras como lugares de convívio e troca de informações. Desse modo, pode-se inferir que o trabalho nesses espaços possibilita o empoderamento da mulher, pois permite uma maior qualidade de vida para ela e para sua família.

\section{REFERÊNCIAS}

FONSECA, A. I. A. Agricultura familiar como sustentabilidade: estudo de caso do Planalto Rural de Montes Claros/MG. Montes Claros: UNIMONTES, 2014. 255p.

FONSECA, A. I. A.; TEIXEIRA, L. dos R.; VIEIRA, K. L.; FONSECA, V. A feira e o mercado: laços de sociabilidade e alternativa de renda para agricultores familiares em Bocaiúva/MG. In: FERREIRA, D. A. de O.; FERREIRA, E. R. (Orgs.). Estudos agrários: conceitos e práticas. Rio Claro: IGCE/UNESP, 2009. 240p.

BARBOSA, C. C.. A feira, a cidade e o turismo: conceitos, definições e relações com o lazer e a cultura em Montes Claros - MG. (Mestrado). Instituto de Geografia. Uberlândia: UFU, 2003.

BARBOSA, E. de C. de S.. O mercado municipal de Montes Claros/MG como categoria geográfica lugar: sua importância para as pessoas que lhe estão próximas. (Monografia). Universidade Estadual de Montes Claros - Centro de Ciências Humanas - Departamento de Geociências. Montes Claros: UNIMONTES, 2012.

BOECHAT, P. T. V.; SANTOS. J. L. dos. Feira Livre: Dinâmicas Espaciais e Relações Indenitárias. Disponível em 〈http://www.uesb.br/eventos/ebg/anais/2p.pdf > . Acesso: dezembro de 2014.

CARNEIRO, M. J. Em que consiste o familiar da agricultura familiar? In: COSTA, L. F. de C.; FLEXOR, G.; SANTOS, R. (Orgs.). Mundo rural brasileiro: ensaios interdisciplinares. Rio de Janeiro: Mauad X; Seropédia, RJ: EDUR, 2008, p.255-269.

HERNÁNDEZ, C. O.. Política de crédito rural com perspectiva de gênero: um meio de "empoderamento" para as mulheres rurais? (Tese). Programa de Pós-Graduação em Desenvolvimento Rural - Faculdade de Ciências Econômicas. Porto Alegre: UFRS, 2009, 248p.

Instituto Brasileiro de Geografia e Estatística - IBGE. Base cartográfica. Disponível em: <http://www.ibge.gov.br>. Acesso: 09/12/2015.

MINISTÉRIO DO DESENVOLVIMENTO AGRÁRIO - MDA. Linhas de crédito do PRONAF. Disponível em: <http://www.mda.gov.br/sitemda/secretaria/saf-creditorural/linhas-de-cr\%C3\%A9dito>. Acesso: 21/12/2015.

RIBEIRO, E. M.; SILVESTRE, L. H.; CASTRO, B. S. de; RIBEIRO, M. B.; AYRES, E. B. A pesquisa nas feiras: histórico e técnicas. In: RIBEIRO, E. M. (coord.). Feiras do Jequitinhonha: mercados, cultura e trabalho de famílias rurais no semi-árido de Minas Gerais. Fortaleza: Universidade Federal de Lavras, 2007. p.83-112.

STROMQUIST, N. La búsqueda del empoderamiento: en qué puede contribuir el campo de la educación? In: LÉON, M. (camp.) Poder y empoderamiento de las mujeres. Santa Fé, Bogotá: tercer mundo editoras. Facultad de Ciencias Humanas, 1997, p. 77-94.

VIEIRA, G. do R. A. L.; FONSECA, A. I. A.; CARDOSO, V. C. dos. A mulher trabalhadora: entre a agricultura e o cuidado com a casa. In: FONSECA, et al (Orgs.) Estudos sobre agroecologia, agricultura familiar e as territorialidades no Norte de Minas Gerais. Montes Claros: Editora Unimontes, 2013. 315p. 